\title{
A automedicação no período de pandemia de COVID-19: Revisão integrativa
}

\author{
Self-medication in the pandemic period of COVID-19: Integrative review \\ Automedicación en el período pandémico de COVID-19: Revisión integrativa
}

\section{Resumo}

O Sars-CoV-2, Coronavírus ou COVID-19, é uma síndrome respiratória de espectro viral evidenciada pela primeira vez em dezembro de 2019 em Wuhan, China. Por ser ainda um vírus pouco conhecido e com potencial letal, a população busca encontrar uma solução rápida e fácil para a doença, como a prática da automedicação. Objetou-se escrever os fatores que corroboram para a prática da automedicação em período de pandemia de COVID-19. Trata-se de uma revisão integrativa da literatura, onde a construção do estudo sustentou-se na pergunta "Quais os fatores que corroboram para a prática da automedicação em período de pandemia de COVID-19?". O levantamento bibliográfico foi realizado no mês de fevereiro de 2021, utilizando as bases de dados Medline, PubMed, Redib e Scielo através dos descritores "Automedicação", "Infecções por Coronavírus", "Educação em Saúde”. Após os critérios de inclusão e 
exclusão, restaram 6 artigos com perfil adequado para a produção desse estudo. Os artigos evidenciaram que a automedicação foi impulsionada no período de pandemia, sendo utilizadas tanto para prevenção como tratamento da COVID-19. O uso irracional de medicamentos tomou frente, por conta dos supostos tratamentos relacionados com a COVID-19.

Palavras-chave: Automedicação; Infecções por coronavírus; Educação em saúde.

\begin{abstract}
Sars-CoV-2, Coronavirus or COVID-19, is a viral spectrum respiratory syndrome first evidenced in December 2019 in Wuhan, China. Because it is still a little known virus with lethal potential, the population seeks to find a quick and easy solution to the disease, such as the practice of self-medication. The object was to write the factors that corroborate the practice of self-medication in a covid-19 pandemic period. This is an integrative review of the literature, where the construction of the study was based on the question "What factors corroborate the practice of self-medication in a period of COVID-19 pandemic?". The bibliographic survey was carried out in February 2021, using the Medline, PubMed, Redib and Scielo databases using the descriptors "Self-medication", "Coronavirus Infections", "Health Education". After the inclusion and exclusion criteria, 6 articles with an adequate profile for the production of this study remained. The articles showed that self-medication was promoted in the pandemic period, being used both for prevention and treatment of COVID-19. The irrational use of medicines has taken on the side of the alleged treatments related to COVID-19.
\end{abstract}

Keywords: Self-medication; Coronavirus infections; Health education.

\title{
Resumen
}

Sars-CoV-2, Coronavirus o COVID-19, es un síndrome respiratorio del espectro viral evidenciado por primera vez en diciembre de 2019 en Wuhan, China. Debido a que todavía es un virus poco conocido con potencial letal, la población busca encontrar una solución rápida y fácil a la enfermedad, como la práctica de la automedicación. El objetivo era escribir los factores que corroboran la práctica de la automedicación en un período pandémico covid-19. Esta es una revisión integrativa de la literatura, donde la construcción del estudio se basó en la pregunta "¿Qué factores corroboran la práctica de la automedicación en un período de pandemia COVID-19?". La encuesta bibliográfica se realizó en febrero de 2021, utilizando las bases de datos Medline, PubMed, Redib y Scielo utilizando los descriptores "Automedicación", "Infecciones por Coronavirus", "Educación para la Salud". Tras los criterios de inclusión y exclusión, se mantuvieron 6 artículos con un perfil adecuado para la producción de este estudio. Los artículos mostraron que la automedicación fue promovida en el período pandémico, siendo utilizada tanto para la prevención como para el tratamiento del COVID-19. El uso irracional de medicamentos ha tomado del lado de los supuestos tratamientos relacionados con el COVID-19.

Palabras clave: Automedicación; Infecciones por coronavirus; Educación para la salud.

\section{Introdução}

O Sars-CoV-2, comumente conhecido como Coronavírus ou COVID-19, caracteriza-se como uma síndrome respiratória de espectro viral na qual teve sua primeira evidência em dezembro de 2019 em Wuhan, China. Rapidamente espalhou-se pelo mundo, sendo declarado em março de 2020 o cenário de pandemia pela Organização Mundial da Saúde (OMS). Atualmente já atingiu cerca de 110 milhões de pessoas e acarretou mais de 2 milhões de mortes em todo o planeta (OMS, 2021).

O isolamento social, o uso de máscaras e álcool gel, bem como a lavagem das mãos são as principais medidas de combate, já que a doença em sua maioria apresenta-se principalmente de forma assintomática. No entanto, a ideia de existir um vírus pouco conhecido associado ao grande número de mortes e internações acometidas desperta na população a sensação de angústia e medo, sendo levados a encontrar uma solução rápida e fácil para a doença, bem como agarrar em ideologias para praticarem o uso da automedicação (ATM) (Carvalho \& Guimarães, 2020).

A ATM caracteriza-se como o ato de utilizar medicamentos de venda livre, ou reutilizar medicamentos prescritos anteriormente sem supervisão médica e/ou multiprofissional, bem como usar fármacos no intuito de tratar sintomas ou doenças autodiagnosticadas (Garcia, et al., 2018).

Essa prática é comum a 77\% dos brasileiros (CFF, 2019). No primeiro trimestre de 2020 houve aumento significativo do consumo de vitaminas e medicamentos que cresceu quase 200\% (CRF-SP, 2020). Entretanto, não há comprovação 
científica absoluta que a utilização de tais fármacos são eficientes ou geram resposta positiva para o tratamento da COVID-19, sendo apenas respaldado em uso experimental. (Filho, et al, 2020). Como consequência, estes apresentaram algumas reações adversas, que se manifestam desde sintomas leves à mais agressivos, a citar: prurido, diarreia, elevação das enzimas hepáticas e cardiotoxicidade (Melo, et al., 2020).

Dessa forma, justifica-se a relevância do presente estudo pela escassez de trabalhos que abordam essa proposta, com a iniciativa de compreender os riscos que a automedicação pode provocar à saúde humana. Bem como, corroborar com o incentivo de boas práticas para o uso racional de fármacos em meio ao cenário atual caótico se faz imprescindível para a saúde coletiva. Portanto, o objetivo deste estudo é descrever os fatores que corroboram para a prática da automedicação em período de pandemia de COVID-19.

\section{Metodologia}

Trata-se de uma revisão integrativa da literatura de estudos envolvendo publicações científicas sobre a automedicação no período de pandemia de COVID-19. A revisão integrativa é um método de revisão mais amplo, pois permite incluir literatura teórica e empírica bem como estudos com diferentes abordagens metodológicas. Os estudos incluídos na revisão são analisados de forma sistemática em relação aos seus objetivos, materiais e métodos, permitindo que o leitor analise o conhecimento pré-existente sobre o tema investigado (Pompeo, Rossi \& Galvão, 2009).

A revisão integrativa é feita a partir da definição de seis etapas: I - estabelecimento da hipótese ou a pergunta da revisão; II - seleção da amostra a ser revista; III - categorização e avaliação dos estudos; IV - interpretação dos resultados; V - apresentação da revisão e VI - síntese do conhecimento (Crossetti, 2015).

Sendo assim, a construção induzida a partir do tema a Automedicação no período de pandemia de COVID-19, resultou na pergunta: Quais os fatores que corroboram para a prática da automedicação em período de pandemia de COVID19? Os descritores utilizados na busca foram: "Automedicação", "Infecções por Coronavírus", "Educação em Saúde”. Para o cruzamento dos descritores em português, inglês e em espanhol, foi utilizado como ferramenta de auxílio, os operadores Booleanos “AND” e "OR" (Quadro 1).

$\mathrm{Na}$ coleta de dados foi realizada a busca de artigos científicos nos bancos de dados, Online Medical Literature Analyses and Retrieval System Online (MEDLINE), Scientific Eletronic Library Online (SCIELO), Medical Publications (PUBMED), Red Iberoamericana de Innovación y Conocimiento Científico (REDIB). Essa busca utilizou as terminologias cadastradas nos Descritores em Ciências da Saúde - DeCs, criados pela Biblioteca Virtual em Saúde (BVS) desenvolvido a partir do Medical Subject Headings (MESH) da U.S. National Library of Medicine, que permite o uso da terminologia comum em português. 
Quadro 1: Estratégia dos Cruzamentos para a busca nas bases de dados, Recife, Pernambuco, 2021.

\begin{tabular}{|c|c|}
\hline Descritores em Português & Descritores em Inglês \\
\hline Automedicação AND "Infecções por Coronavírus" & "Self Medication" AND "Coronavirus Infections" \\
\hline Automedicação OR "Infecções por Coronavírus" & "Self Medication" AND "Coronavirus Infections" \\
\hline $\begin{array}{l}\text { "Infecções por Coronavírus" AND "Educação em } \\
\text { Saúde" }\end{array}$ & "Coronavirus Infections" AND "Health Education" \\
\hline $\begin{array}{l}\text { "Infecções por Coronavírus" OR "Educação em } \\
\text { Saúde" }\end{array}$ & "Coronavirus Infections" OR "Health Education" \\
\hline "Educação em Saúde" AND Automedicação & "Health Education” AND “Self Medication" \\
\hline "Educação em Saúde" OR Automedicação & "Health Education" OR "Self Medication" \\
\hline $\begin{array}{l}\text { Automedicação AND “Infecção por Coronavírus” OR } \\
\text { "Educação em Saúde”" }\end{array}$ & $\begin{array}{l}\text { "Self Medication" AND "Coronavirus Infections" } \\
\text { OR "Health Education" }\end{array}$ \\
\hline $\begin{array}{l}\text { Automedicação AND "Infecção por Coronavírus" } \\
\text { AND "Educação em Saúde" }\end{array}$ & $\begin{array}{l}\text { "Self Medication" AND "Coronavirus Infections" } \\
\text { AND "Health Education" }\end{array}$ \\
\hline $\begin{array}{l}\text { Automedicação OR "Infecção por Coronavírus" OR } \\
\text { "Educação em Saúde" }\end{array}$ & $\begin{array}{l}\text { "Self Medication" OR "Coronavirus Infections" OR } \\
\text { "Health Education" }\end{array}$ \\
\hline
\end{tabular}

Fonte: Autores (2021).

A busca foi realizada em Fevereiro de 2021. Foram analisados e selecionados os estudos de interesse da pesquisa, conforme os enfoques temáticos, cenários das pesquisas, metodologia aplicada e período de publicação. Como critérios de inclusão foram selecionados artigos completos publicados em português, em inglês e em espanhol; que apresentavam especificidade com o tema e a problemática do estudo; que contivessem os descritores selecionados e aqueles publicados entre os anos de 2019 a 2021. Foram excluídos os artigos que não atendiam a temática proposta; revisões bibliográficas, integrativas e sistemáticas, editoriais, teses, dissertações, monografias e protocolos. Foram encontrados 257 artigos, dos quais realizou-se a leitura criteriosa e flutuante, e desses, 6 (seis) se enquadraram na pesquisa. Após essa etapa foi executada a análise deles (Pereira, et al., 2018).

\section{Resultados e Discussão}

Para sistematizar a busca e seleção dos artigos (Figura 1) utilizou-se a recomendação do Preferred Reporting Items for Systematic Reviews and MetaAnalyses (PRISMA) (Moher, et al., 2009). 
Figura 1. Fluxograma com representação de elegibilidade e inclusão de artigos na seleção dos estudos, 2021.

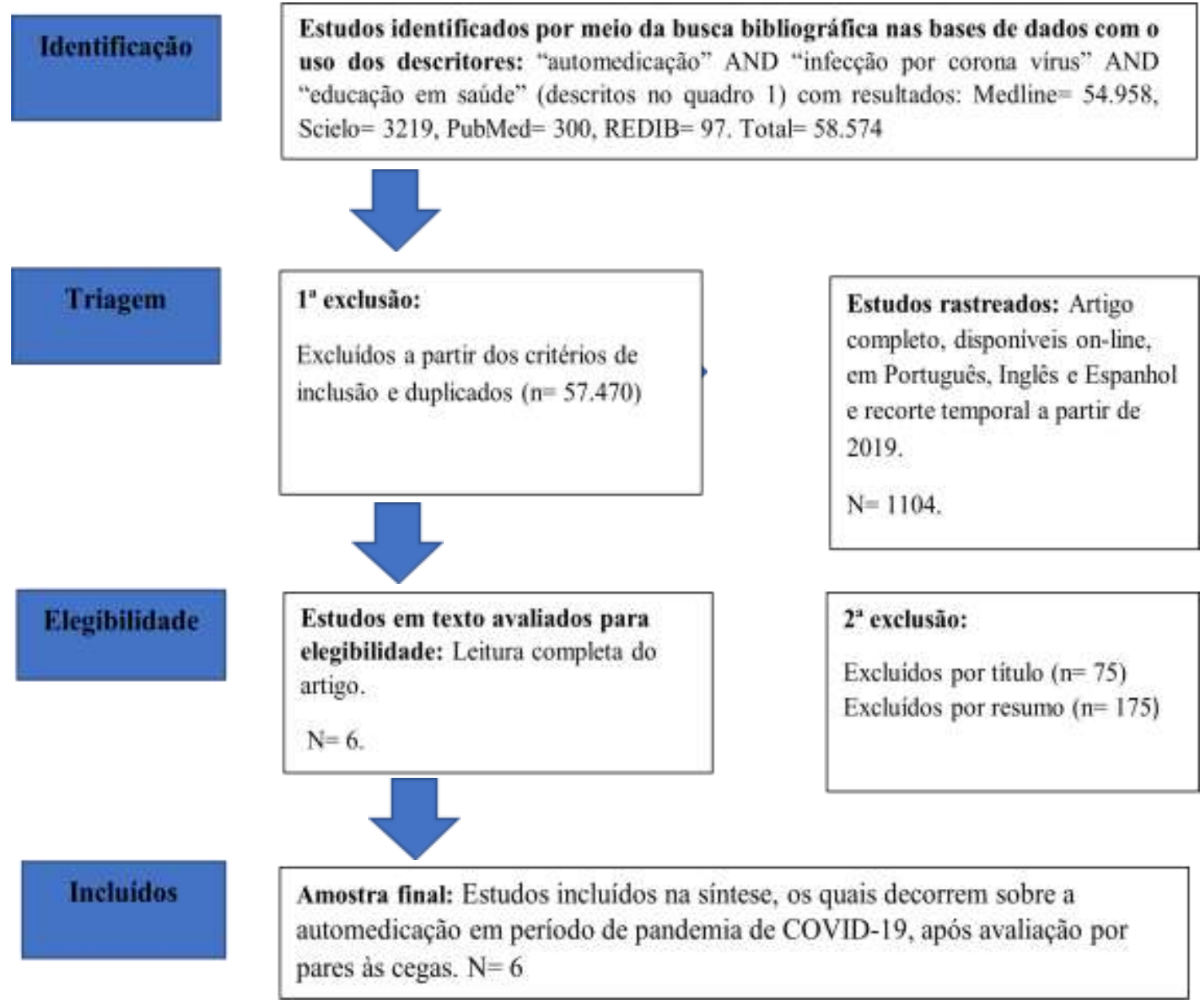

Modelo adaptado do fluxograma PRISMA. Fonte: Autores (2021).

Os artigos científicos, incluídos nesta revisão, estão descritos no Quadro 2, que mostram: o número, base de dados, título do artigo, autor (es), metodologia aplicada, ano da publicação, objetivos e síntese dos resultados. 
Quadro 2. Distribuição dos resultados, nos artigos selecionados, sobre a automedicação no período de COVID-19, Recife, Pernambuco, 2021.

\begin{tabular}{|c|c|c|c|c|c|c|}
\hline Número & $\begin{array}{c}\text { Base de } \\
\text { publicação }\end{array}$ & Autor/Ano & Título & Método & Objetivos & Resultados \\
\hline A1 & Medline & $\begin{array}{l}\text { SADIO et. al., } \\
2021 .\end{array}$ & $\begin{array}{l}\text { Assessment of self- } \\
\text { medication practices in } \\
\text { the context of the covid- } \\
19 \text { outbreak in togo. I } \\
\text { avaliação das práticas } \\
\text { de automedicação no } \\
\text { contexto do surto de } \\
\text { covid-19 no togo. }\end{array}$ & $\begin{array}{l}\text { Estudo } \\
\text { transversal. }\end{array}$ & $\begin{array}{l}\text { Estimar a } \\
\text { prevalência de } \\
\text { automedicação } \\
\text { para prevenir o } \\
\text { COVID-19 e seus } \\
\text { fatores associados } \\
\text { em Lomé, Togo. }\end{array}$ & $\begin{array}{l}\text { O estudo confirmou que a } \\
\text { automedicação era } \\
\text { motivada principalmente } \\
\text { para uso preventivo e não } \\
\text { para tratamento de } \\
\text { manifestações clínicas } \\
\text { específicas de COVID-19. }\end{array}$ \\
\hline A2 & Medline & $\begin{array}{l}\text { MAKOWSK } \\
\text { A et. al., } \\
2020 .\end{array}$ & $\begin{array}{l}\text { Self-Medication-Related } \\
\text { Behaviors and Poland's } \\
\text { COVID-19 Lockdown. I } \\
\text { Comportamentos } \\
\text { relacionados à } \\
\text { automedicação e } \\
\text { bloqueio COVID-19 da } \\
\text { Polônia. }\end{array}$ & $\begin{array}{l}\text { Estudo } \\
\text { amostral. }\end{array}$ & $\begin{array}{lr}\text { Analisar se as } \\
\text { mudanças e } \text { a } \\
\text { imposição de um } \\
\text { bloqueio de } & \text { três } \\
\text { meses fizeram } & \\
\text { com que } & \text { os } \\
\text { poloneses } & \text { se } \\
\text { envolvessem em } \\
\text { comportamentos } \\
\text { relacionados à } \\
\text { automedicação. }\end{array}$ & 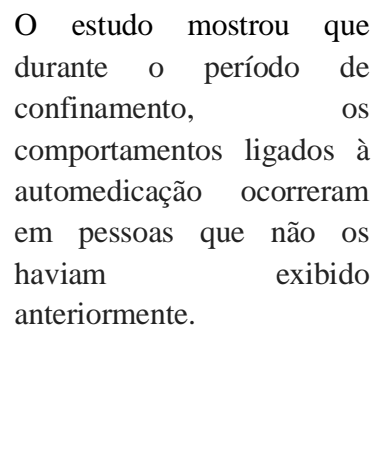 \\
\hline A3 & Medline & $\begin{array}{l}\text { QUISPE- } \\
\text { CAÑARI et. } \\
\text { al., } 2020 .\end{array}$ & $\begin{array}{l}\text { self-medication } \\
\text { practices during the } \\
\text { covid-19 pandemic } \\
\text { among the adult } \\
\text { population in peru: a } \\
\text { cross-sectional survey. / } \\
\text { práticas de } \\
\text { automedicação durante } \\
\text { a pandemia covid-19 } \\
\text { entre a população adulta } \\
\text { no peru: } \\
\text { levantamento um } \\
\text { transversal. }\end{array}$ & $\begin{array}{l}\text { Estudo } \\
\text { multicêntric } \\
\text { o } \\
\text { transversal. }\end{array}$ & $\begin{array}{l}\text { Objetivo avaliar a } \\
\text { prevalência de } \\
\text { medicamentos } \\
\text { automedicados } \\
\text { para sintomas } \\
\text { respiratórios, } \\
\text { como COVID-19 } \\
\text { preventivos, para } \\
\text { os seus sintomas } \\
\text { ou após teste } \\
\text { positivo. }\end{array}$ & $\begin{array}{l}\text { Observou-se que } 1661 \\
(43,9 \%) \text { entrevistados } \\
\text { relataram ter se } \\
\text { automedicado durante a } \\
\text { pandemia, o principal } \\
\text { motivo para o ato, foi por } \\
\text { relatar que estava } \\
\text { gripado(a). } \\
\text { percentual foi visualizado } \\
\text { uma porcentagem relevante, } \\
\text { quando se refere drogas } \\
\text { relacionadas ao COVID-19: } \\
\text { como prevenção, presença } \\
\text { de sintomas e caso } \\
\text { confirmado. }\end{array}$ \\
\hline A4 & Scielo & $\begin{array}{l}\text { DO BU et. al., } \\
2020 .\end{array}$ & $\begin{array}{l}\text { Representações } \\
\text { ancoragens sociais do } \\
\text { novo coronavírus e do } \\
\text { tratamento da COVID- } \\
19 \text { por brasileiros. I } \\
\text { Representations and } \\
\text { social anchorages of the } \\
\text { new coronavirus and } \\
\text { the COVID-19 } \\
\text { treatment by Brazilians. }\end{array}$ & $\begin{array}{l}\text { Estudo } \\
\text { misto, } \\
\text { quantitativo } \\
\text { e } \\
\text { qualitativo, } \\
\text { descritivo e } \\
\text { exploratório } \\
\text { - }\end{array}$ & $\begin{array}{l}\text { Objetivou-se neste } \\
\text { estudo apreender a } \\
\text { gênese das } \\
\text { representações } \\
\text { sociais do novo } \\
\text { coronavírus, bem } \\
\text { como do } \\
\text { tratamento da } \\
\text { COVID-19, } \\
\text { considerando-se } \\
\text { diferentes } \\
\text { ancoragens sociais } \\
\text { de brasileiros. }\end{array}$ & $\begin{array}{l}\text { O estudo mostrou que os } \\
\text { participantes com renda } \\
\text { entre um e dois salários } \\
\text { mínimos, estão mais } \\
\text { propensos a } \\
\text { automedicarem, é uma } \\
\text { prática comum entre as } \\
\text { pessoas que apresentam os } \\
\text { sintomas da COVID-19. }\end{array}$ \\
\hline
\end{tabular}




\begin{tabular}{|c|c|c|c|c|c|c|}
\hline A5 & PubMed & $\begin{array}{l}\text { ONCHONGA } \\
\text { et. al., } 2020 .\end{array}$ & $\begin{array}{l}\text { Assessing the } \\
\text { prevalence of self- } \\
\text { medication among } \\
\text { healthcare workers } \\
\text { before and during the } \\
2019 \text { SARS-CoV-2 } \\
\text { (COVID-19) pandemic } \\
\text { in Kenya. / Avaliação } \\
\text { da prevalência de } \\
\text { automedicação entre os } \\
\text { profissionais de saúde } \\
\text { antes e durante a } \\
\text { pandemia SARS-CoV-2 } \\
2019 \text { no Quênia. }\end{array}$ & $\begin{array}{l}\text { Amostrage } \\
\mathrm{m} \\
\text { estratificada } \\
\text {. }\end{array}$ & $\begin{array}{l}\text { Avaliar a } \\
\text { prevalência de } \\
\text { automedicação } \\
\text { antes e durante o } \\
\text { surto de pandemia } \\
\text { COVID-19 entre } \\
\text { os profissionais de } \\
\text { saúde e seus } \\
\text { fatores associados. }\end{array}$ & $\begin{array}{l}84,2 \% \text { dos entrevistados } \\
\text { relataram o aumento do } \\
\text { desejo de se automedicar } \\
\text { por conta da pandemia do } \\
\text { Covid-19. A } 50,9 \% \text { alegou } \\
\text { ingerir algum medicamento } \\
\text { por conta própria por } \\
\text { apresentar sintoma } \\
\text { sugestivo de Covid- } 19 .\end{array}$ \\
\hline A6 & REDIB & $\begin{array}{l}\text { SOUZA et. } \\
\text { al., } 2021 .\end{array}$ & $\begin{array}{l}\text { Aparición de la } \\
\text { automedicación en la } \\
\text { población brasileña } \\
\text { como } \\
\text { preventiva del SARS- } \\
\text { CoV-2. / Occurrence of } \\
\text { Self-medication in the } \\
\text { Brazilian population as } \\
\text { apreventive strategyfor } \\
\text { SARS-CoV-2. } \\
\text { Ocorrência } \\
\text { Automedicação na } \\
\text { população Brasileira } \\
\text { como de } \\
\text { preventiva ao SARS- } \\
\text { CoV-2. }\end{array}$ & $\begin{array}{c}\text { Estudo } \\
\text { descritivo e } \\
\text { analítico, de } \\
\text { natureza } \\
\text { qualitativa. }\end{array}$ & $\begin{array}{l}\text { Objetivou-se } \\
\text { identificar a } \\
\text { existência de } \\
\text { automedicação } \\
\text { por pessoas com o } \\
\text { objetivo de } \\
\text { prevenir o SARS- } \\
\text { CoV-2 e analisar } \\
\text { o potencial de } \\
\text { agravamento } \\
\text { desse uso ao } \\
\text { organismo } \\
\text { humano. }\end{array}$ & $\begin{array}{l}30,8 \% \text { relataram se } \\
\text { automedicar no intuito de } \\
\text { fortalecer a imunidade. A } \\
\text { origem de aquisição dos } \\
\text { fármacos constatou cerca de } \\
91,2 \% \text { em farmácia } \\
\text { comercial. }\end{array}$ \\
\hline
\end{tabular}

Fonte: Autores (2021).

Os seis estudos foram divididos em três categorias com base no título e no assunto abordado (Quadro 3), para que pudessem ser mais bem explorados.

Quadro 3. Categorização dos artigos.

\begin{tabular}{|l|l|}
\hline $\begin{array}{l}\text { A utilização da automedicação como meio preventivo contra } \\
\text { COVID-19. }\end{array}$ & A1; A6. \\
\hline $\begin{array}{l}\text { Automedicação como forma de diminuir a sintomatologia } \\
\text { sugestiva ou confirmada de COVID-19 }\end{array}$ & A3; A5. \\
\hline $\begin{array}{l}\text { Perfil sociodemográfico de comportamentos relacionados a } \\
\text { automedicação }\end{array}$ & A2; A4. \\
\hline
\end{tabular}

Fonte: Autores (2021).

Os estudos trouxeram abordagens amplas e diferentes nas pesquisas sobre a automedicação no período de pandemia de COVID-19, desde os títulos até a abordagem metodológica. No que se diz respeito a esse aspecto, o processo de metodologia dos estudos apresentou-se em grande parte em estudo transversal (1), estudo amostral (1), estudo multicêntrico transversal (1), estudo misto (1), estudo amostral estratificado e estudo descritivo, analítico de natureza qualitativa (1). Ressalta-se que alguns estudos trouxeram mais de um tipo de abordagem. 
Em relação ao local de publicação e pesquisas dos estudos, 2 destes são do Brasil, 1 do Peru, 1 da Polônia, 1 do Togo e 1 do Quênia. Importante ressaltar a influência da COVID-19 em todo o mundo, fazendo com que diversos países investissem e pesquisassem o tema.

Devido à falta de fármacos que atuem como profilático, ou que auxiliem de maneira direta ao tratamento da COVID19, tem-se observado uma intensificação comportamental da população em se automedicar, acreditando que assim estarão mais seguras (OMS, 2020). A grande da procura e uso de suplementos alimentares, como vitaminas e minerais, para fortalecer a imunidade e prevenir a infecção pelo vírus, assim como, fármacos com propriedade antiparasitária ou antibiótica tem ocorrido consideravelmente durante esta pandemia (Pereira, 2020).

A situação provoca, desde então, preocupantes impactos sociais, econômicos e graves consequências para o sistema de saúde global. A automedicação tem sido de grande preocupação aos serviços de saúde, pois, o acesso a assistência médica juntamente com medicamentos, não implica em melhores condições de saúde ou até mesmo, qualidade de vida, pois as falhas na dispensação, o uso de medicamentos por conta própria pode levar a tratamentos que são ineficazes e nada seguros (Oliveira, et al., 2020).

Segundo Souza et al. (2021), 157 (30,1\%) dos participantes quando indagados sobre a realização de automedicação no intuito de prevenir ou tratar a infecção pelo SARS-CoV-2, relataram ter se automedicado. O uso indevido de medicação, sem a prescrição de profissionais habilitados, pode causar agravamento de doenças, intoxicação, surgimento de reações adversas e resistência a medicamentos, desestabilizando o pleno funcionamento do organismo.

Quanto aos participantes que realizaram a automedicação no presente período pandêmico, houve destaque para os fármacos Ivermectina $(52,8 \%)$ e Azitromicina $(14,2 \%)$, e, em relação ao suplemento vitamínico, houve prevalência das vitamina C (66,4\%) e D (10,9\%), sendo estes os mais utilizados para prevenir ou tratar infecções pelo SARS-CoV-2, mesmo alguns deles não possuírem comprovação científica sobre eficácia. Atualmente, não existem agentes terapêuticos contra o vírus, e, as pesquisas em desenvolvimento sugerem uma considerável lista de medicamentos com efeitos farmacológicos apropriados e eficácia terapêutica no tratamento de pacientes com a COVID-19 (Souza, et al., 2021).

Ainda sobre o assunto, Souza et al. (2021) afirma que a grande maioria dos entrevistados $(91,2 \%)$ afirmou ter adquirido fármacos sem prescrição médica em farmácias comerciais, e, quando indagados sobre o conhecimento dos potenciais riscos da automedicação bem como dos efeitos colaterais que podem surgir, houve uma predominância de pessoas que afirmaram conhecer os efeitos adversos. Sendo assim, devida à falta de acessibilidade aos serviços médicos, as farmácias comerciais, se destacam como o principal meio para a prática da automedicação entre a população, facilitada pelo acesso rápido ao medicamento nas farmácias.

Corroborando com o estudo, Sadio et al. (2021), apresenta que $334(34,2 \%)$ participantes da pesquisa utilizaram fármacos para tratamento e profilaxia do COVID-19 sem prescrição médica. Esses índices estão relacionados com desinformação sobre o uso de supostos preventivos contra COVID-19, outro fator correlacionado, é a facilidade de aquisição de fármacos em farmácias, facilitando o uso dos mesmo sem encaminhamento médico.

Um estudo realizado no Brasil constatou que apesar de já existirem normas para combate à compra sem receita, uma grande parte dos usuários, estão esclarecidos sobre a ilegalidade da compra de certos fármacos sem prescrição médica. A prática de ingestão de fármacos sem a prescrição médica, o aconselhamento e o acompanhamento de um profissional de saúde gabaritado se configura como automedicação (Santos, et al., 2018).

No que se refere aos fármacos em destaque e que foram utilizados como profilático ou para o tratamento de COVID19, Sadio et al. (2021), afirma que os fármacos mais usados, segundo conta o estudo, foram: Vitamina C (27,6\%), Cloroquina/Hidroxicloroquina que foi utilizada por (2,0\%) da amostra, e a Azitromicina foi utilizada por (1,2\%). O uso de Cloroquina/Hidroxicloroquina pode estar ligado ao fato de que um estudo publicado em março de 2020 concluiu que a 
hidroxicloroquina era eficaz para a redução da carga viral no uso em casos graves da doença. No entanto, houve muitos avisos sobre o uso inadequado de Cloroquina/Hidroxicloroquina fora das configurações hospitalares ou clínicas para COVID-19. Seu uso pode aumentar o risco de arritmias ou morte (Baker, 2020; Mégarbane,2020; Kapoor, et al., 2020).

A utilização de medicamentos sem prescrição médica pode causar danos ao paciente e aumentar o risco de resistência antimicrobiana, exemplo ao antibiótico azitromicina. A baixa prevalência do uso de Azitromicina apresentadas no estudo de Sadio et al. (2021), poderia ser explicada pelo seu custo relativamente alto e pelo fato de que, nos últimos anos, a associação de farmacêuticos togoleses tem insistido para que esses produtos sejam vendidos apenas com prescrição médica, mesmo a necessidade de uma prescrição não ser regulamentada por lei. Diferentemente dos dados apresentados nos estudos de Souza et al. (2021), que 14,2\% do participantes afirmaram ter usado a Azitromicina com profilático para o tratamento ou para a profilaxia do SARS-Co2.

De acordo com o estudo feito por Quispe-Cañari et al. (2020) na cidade do Peru, durante a pandemia de COVID-19, uma parcela considerada dos participantes da pesquisa disse que se automedicaram, ao apresentarem sintomatologia sugestiva de teste positivo para SARS-CoV-2, também foi observado o uso de automedicação quando diagnosticado como COVID-19 positivo. Constatou-se que $118(31,1 \%)$ entrevistados consumiam os medicamentos que habitualmente são utilizados para o tratamento ou com profilático do Novo coronavírus, mesmo alguns não possuírem comprovação científica.

Observou-se que uma parcela dos entrevistados se automedicou por outras razões, que poderiam ser atribuídas à ampla utilização dos medicamentos. Ainda sobre a pesquisa, os entrevistados mais velhos apresentaram maior frequência de automedicação. Isso pode ser causado pela percepção de que qualquer substância farmacológica poderia ter um efeito positivo contra a infecção viral COVID-19 (Quispe-cañari, et al., 2020).

A automedicação é mais comum em países onde os sistemas de saúde tendem a ser menos eficazes devido ao longo tempo de espera em estabelecimentos de saúde, à dificuldade em obter consultas médicas, ao estoque insuficiente de medicamentos essenciais, à falta de atenção e à quantidade insuficiente de leitos/espaço disponíveis nas unidades de saúde (Parulekar, et al., 2016).

Segundo Onchonga et al. (2020) a prevalência global de automedicação aumentou de $(36,2 \%)$ antes da pandemia para $(60,4 \%)$ durante a pandemia. Já segundo Quispe-cañari et al. (2020) constatou-se, que 193 (50,9\%) dos participantes alegou ingerir algum medicamento por conta própria por apresentar sintoma sugestivo de COVID-19. Esses resultados corroboram com um estudo semelhante, que apresenta um percentual relevante quando se trata de ingesta de medicamento não prescritos por um profissional habilitado, por apresentar sintomas sugestivo de COVID-19 positivo.

Desta forma, a desinformação, o negacionismo à ciência e, como consequência, o uso irracional de alguns medicamentos e o não cumprimento do isolamento social, mesmo quando possível, também são dificuldades frequentes que retardam o combate ao novo coronavírus. A negação da ciência talvez seja um dos principais fatores que, no cenário da pandemia, influencie as pessoas a se automedicarem e, assim, correrem riscos com a saúde, uma vez que se cria uma falsa sensação de proteção contra a COVID-19 que, associada à descrença científica, culminam no desrespeito do isolamento social e, consequentemente, no crescimento da curva de infectados (Luccheta \& Mastroianni, 2019; Carvalho \& Guimarães, 2020).

No que diz respeito a categoria "Perfil sociodemográfico de comportamentos relacionados a automedicação", um estudo realizado na Polônia evidenciou a relação da prática da automedicação com o viés sociodemográfico através da categoria: prática religiosa e a presença de crianças menores de 18 anos que residem com os pais, sendo 90,6\% e 39,5\% respectivamente (Makowska, et al., 2020).

Esse dado se sustenta quando Makowska et. al (2020) afirma que a religião é frequentemente associada ao bem-estar, qualidade de vida e saúde. Desse modo, indivíduos religiosos se adaptam rapidamente aos problemas de saúde e consequentemente respondem melhor ao tratamento. 
Cabe também ressaltar que a religiosidade desperta de forma positiva ou negativa a confiança em informações obtidas através de fontes informais, tais como: familiares, amigos, líderes espirituais, sites religiosos, entre outros. Tal situação embasada na fé, propicia com que fiéis adotem para si informações não verificadas acerca da eficácia de medicamentos, colocando em risco a sua saúde (Makowska, et al., 2020).

Seguindo a mesma linha de raciocínio, a presença de crianças menores de 18 anos em um domicílio corrobora para que os pais deixem sua saúde de lado e priorizem a de seus filhos, gerando oportunidades para a automedicação. Soma-se a isso o confinamento associado ao medo de ir em locais de alta circulação contaminante, como hospitais e consultórios, acarretando na decisão de autodiagnóstico, e consequentemente na automedição (Makowska et. al., 2020).

Em contrapartida, o estudo de Bú et al. (2020) expõe a categoria "renda" como fator predisponente para a automedicação. Participantes que possuíam entre um a dois salários mínimos relataram com frequência o uso de tal prática, incluindo paracetamol, dipirona, antitérmico, nebulização e chá como terapias profiláticas para a coronavírus.

Um fator que chama atenção é o índice de escolaridade destacado na pesquisa, uma vez que apresenta indivíduos com ensino médio completo em confronto com participantes que possuem escolaridade até o ensino superior, dado que o primeiro grupo destaca ações de prevenção voltadas para o coletivo, utilizando palavras como atenção; cuidado e respeito, enquanto que o segundo grupo enfatiza a compra de itens específicos para a proteção individual, como máscaras; luvas e álcool gel e na aquisição de medicamentos (Bú, et al., 2020).

Esse achado pode sinalizar que o maior acesso da população escolarizada à internet ou a veículos midiáticos, bem como sua capacidade de compreensão das informações, levam estes a assumirem uma autonomia muito maior na tomada de decisões para adquirir medicamentos, tomá-los e talvez até dar a outras pessoas que tem acesso a eles.

\section{Conclusão}

Diante do exposto, o consumo demasiado de fármacos de forma errada pela população aumentou consideravelmente. O uso irracional de medicamentos tomou frente, por conta dos supostos tratamentos para a Covid-19. Vale ressaltar que, até o momento, não há nenhuma evidência científica conclusiva que possa corroborar com o uso de determinados medicamentos para o tratamento ou profilaxia contra o coronavírus.

Logo, posteriores trabalhos, perante esse tema deverão levar em consideração os mais diversos problemas que a automedicação pode vir a trazer, bem como os riscos da ingestão indiscriminada de antibióticos e das possíveis interações medicamentosas que podem vir a ocorrer, é importante salientar o cuidado com o processo de medicação e a filtragem de informações divulgadas pela mídia frente aos cuidados que devem ser realizados diante o SARS-CoV-2.

\section{Referências}

Baker A.(2020). Poderia funcionar como uma cura? Talvez. Um remédio à base de plantas para coronavírus é um sucesso na África, mas especialistas têm suas dúvidas. Research, Society and Development,

Carvalho, W. \& Guimarães, Á. (2020) Desinformação, Negacionismo e Automedicação: a relação da população com as drogas "milagrosas" em meio à pandemia da COVID-19. InterAmerican Journal of Medicine and Health, v. 3.

CFF. (2020). Médico versus Internet: os perigos do hábito de autodiagnóstico na pandemia. [blog] /www.cff.org.br/noticia.php?id=5880\&titulo =M\%C3\%A9dico+versus+Internet\%3A+os+perigos+do+h\%C3\%A1bito+de+autodiagn\%C3\%B3stico+na+pandemia.

CRF-SP. (2020). Alerta sobre o aumento da automedicação durante a pandemia. Informativos Técnicos - CRF-SP [blog] Conselho Regional de Farmácia do Estado de São Paulo.

Crossetti, M. G, O. (2015). Revisão integrativa de pesquisa na enfermagem: o rigor científico que lhe é exigido. Revista Gaúcha de Enfermagem, 33(2), 08-13.

Filho, P. S. et al. (2020). Riscos da automedicação em idosos acometidos pelo coronavírus e outras síndromes respiratórias. Research, Society and Development, 9(7), e458974211-e458974211. 
Do bú, E. A. et al. (2020). Representações e ancoragens sociais do novo coronavírus e do tratamento da COVID-19 por brasileiros. Estud. psicol. (Campinas), (37), e200073. https://doi.org/10.1590/1982-0275202037e200073.

Garcia, A. L. F. et al. (2018). Automedicação e adesão ao tratamento medicamentoso: avaliação dos participantes do programa Universidade do Envelhecer. Revista Brasileira de Geriatria e Gerontologia, 21(6), 691-700.

Kapoor A, Pandurangi U, Arora V, Gupta A, Jaswal A, Nabar A, et al. (2020). Riscos cardiovasculares de hidroxicloroquina no tratamento e profilaxia de pacientes COVID-19: Uma declaração científica da Indian Heart Rhythm Society. Indian Pacing Electrophysiol J. S0972-6292(20):300383. https://doi.org/10.1016/j.ipej.2020.04.003.

Luccheta, C. R., \& Mastroianni, P. C. (2019) Rational use of chloroquine and hydroxychloroquine in times of COVID-19. Revista de Ciências Farmacêuticas Básica e Aplicada. 40:e643.

Makowska, M.; Boguszewski, R.; Nowakowski, M.; \& Podkowińska, M. (2020). "Self-Medication-Related Behaviors and Poland's COVID-19 Lockdown" Int. J. Environ. Res. Public Health, 17(22), 8344. https://doi.org/10.3390/ijerph1722834.

Melo, J. R. R. et al. (2021). Reações adversas a medicamentos em pacientes com COVID-19 no Brasil: análise das notificações espontâneas do sistema de farmacovigilância brasileiro. Cadernos de Saúde Pública, 37, e00245820.

Mégarbane B. (2020). Cloroquina e hidroxicloroquina para tratar COVID-19: entre esperança e cautela. Clin Toxicol (Phila). 12. https://doi.org/10.1080/15563650.2020.1748194.

Moher, D., Liberati, A., Tetzlaff, J., Altman, D. G. (2009). Preferred Reporting Items for Systematic Reviews and Meta Analys es: The PRISMA Statement. PLoS Medicine, 6(7), e1000097.

OMS. (2020). Folha informativa-COVID-19 (doença causada pelo novo coronavírus). https://www.paho.org/bra/index.php?option=com_content\& view $=$ article $\&$ id $=6101:$ covid $19 \&$ Itemid $=875$.

OMS. (2021). Painel doença coronavírus da OMS (COVID-19). https://covid19.who.int/.

Oliveira, A. G. L. et al. (2020). Os riscos da automedicação no tratamento do covid-19: uma revisao de literatura. Centro Universitário Católica de Quixadá. 4200-12964-1-PB.pdf.

Onchonga D. et. al. (2019). Assessing the prevalence of self-medication among healthcare workers before and during the SARS-CoV-2 (COVID-19) pandemic in Kenya. Saudi Pharm J. 28(10):1149-1154. doi: 10.1016/j.jsps.2020.08.003.

Parulekar M, Mekoth N, C.M. Ramesh, Parulekar A. (2016). Automedicação em países em desenvolvimento uma revisão sistemática J. Pharm. Technol. Res. Manage. 4(2), 10.15415/jptrm.2016.42007.

Pereira, M. S. (2020). Pandemia: os riscos da automedicação e os cuidados com a saúde. https://www.unisc.br/pt/noticias/pandemia-os-riscos-daautomedicacao-e-os-cuidados-com-a-saude.

Pereira, A. S. et al. (2018). Metodologia da pesquisa científica. UFSM. https://www.ufsm.br/app/uploads/sites/358/2019/02/Metodologia-da-PesquisaCientifica_final.pdf

Pompeo, D. A; Rossi, L. A; Galvao, C. M. (2009). Revisão integrativa: etapa inicial do processo de validação de diagnóstico de enfermagem. Acta Paul. Enferm. 22(4), 434-438.

Quispe-cañar, J. F. et. al. (2020). Self-medication practices during the COVID-19 pandemic among the adult population in Peru: A cross-sectional survey. Saudi Pharmaceutical Journal. 29(1), 1-11. https://doi.org/10.1016/j.jsps.2020.12.001.

Santos, M. F. F, Pereira, V. C. R, Guimarães Jr, P. R \& Lúcio N. M. P. (2020). Analysis of antimicrobial consumption in a community pharmacy in 2018. Research, Society and Development, 9(7), 1-15, e378974278.

Silva, J. P; Batista, L. O. (2020). Impactos da automedicação em tempos de pandemia COVID-19. SC: UNESC, 2020. 74-75

Souza, M. N.C. et. al., (2021). Ocorrência de Automedicação na população brasileira como estratégia preventiva para SARS-CoV-2. Pesquisa, Sociedade e Desenvolvimento, 10(1), e44510111933, 2021. 10.33448/rsd-v10i1.11933. 